\title{
OPEN
}

\section{2 \\ Pharmaceuticals in Kenya: The Evolution of Technological Capabilities}

\author{
Roberto Simonetti, Norman Clark and Watu Wamae
}

\section{Introduction}

As Chapter 1 briefly outlined, Kenya has a strong and long-standing pharmaceutical industry. A 2015 Business Monitor report on pharmaceutical manufacturing in Kenya states that the country hosts the largest pharmaceutical industrial base in East Africa. The report also sees a bright future as a 'potential base for export across East Africa' (BMI Research, 2015). This chapter locates the Kenyan pharmaceutical industry within the country's historical context of industrial development and growth.

The features of the local production of medicines are shaped by the characteristics of the Kenyan economic and industrial systems, which in turn are the product of its economic history. To analyse this shaping, this chapter briefly presents and then applies an evolutionary economic understanding of industrial capabilities, focusing particularly on technological capabilities at the firm and industrial system level, their sources and evolution. This framework of industrial analysis is also used in a number of subsequent chapters in this book. It is particularly illuminating for the analysis of the development of an industry, pharmaceuticals, that is technologically demanding relative to the industrial and economic context in a low-income country such as Kenya.

Pharmaceutical manufacturers face constant competitive and regulatory pressure to upgrade their technological capabilities, and the evolutionary framework of analysis emphasizes the extent to which this upgrading relies on both firm-level investment building on existing capabilities, and also on the benefits that accrue from its surrounding industrial base. Chapter 1 briefly noted that African countries' broader 
industrial base frequently stems in turn from an era of policy-led import-substituting industrialization. This chapter explores in more detail how the pharmaceutical industry has built on this basis in Kenya, and the scope that gives the industry for exploiting the opportunities opened up by the subsequent more liberalized and competitive markets. It also outlines some of policy decisions that have shaped the industry's development, and some of the challenges for firms and policy makers.

This chapter draws on a range of sources, including trade and manufacturing data, secondary published and grey literature sources and also interviews with manufacturers and distributors and other field data collected in $2012-14 .^{1}$

\section{The evolution of Kenya's pharmaceutical industry in the context of post-colonial industrialization}

The profile of the pharmaceutical industry in Kenya is influenced by the country's broader economic and industrial history. The post-independence industrial history of Kenya can be split into three periods according to the policy regimes adopted: the early years of import substitution industrialization (ISI), until the 1970s; the liberalization and gradual opening up of the economy in the 1980s and 1990s; and the new millennium (Chege, Ngui and Kimiyu, 2014).

Pharmaceutical production was already taking place before the advent of independence in 1963, as Chapter 1 described. The early firms were mainly foreign direct investments (FDI). The newly independent country then continued to implement policies of ISI that had started during the colonial period.

Import-substituting industrialization is a set of economic and trade policies that aim to promote domestic industrialization in order to reduce the country's dependence on manufacturing from abroad. The policies seek to promote the accumulation of skills, capital and knowledge for the production of manufacturing goods by limiting imports of selected manufacturing goods through a variety of trade restrictions and subsidizing domestic manufacturing enterprises. In the Kenyan case, local producers were shielded from foreign competition in manufactures in a variety of ways. High tariffs, even reaching 100\% of the goods' value, and quotas were imposed on imported manufactures, which were also charged higher rail fares, with the result that their prices were high for Kenyan consumers. Domestic manufacturing firms were also helped with financial subsidies, allocated land for production facilities, and 
allowed to have import duties refunded on the inputs (raw materials and equipment) they had to import for production.

The Kenyan government also explicitly welcomed foreign-owned firms who set up production facilities in the country, as they contributed to the domestic industrial development. The large weight of FDI in Kenyan industry of the colonial period is also typical of the early years of independence, when it even reached half of industrial output (Maxon, 1992). Fearing a flight of FDI, a year after independence, in 1964, the government passed the Foreign Investment Act, which gave reassurances to foreign firms in areas such as repatriation of profits and protection from nationalization.

This policy orientation towards manufacturing for the domestic market was reinforced in the 1970s by balance-of-payments crises and rising oil prices which led to scarcity of foreign exchange. Manufacturing of consumer goods for the local market expanded rapidly in the early 1970s, and there was diversification into upstream supplier industries such as plastics. In this period, pharmaceutical manufacturing expanded, benefitting from the industrial protection, and also from an active government policy to promote investment and technological upgrading. Laboratories \& Allied was incorporated in 1970. The government established the Industrial and Commercial Development Corporation (ICDC) to promote the inclusion of local people in industry by providing development finance and technical assistance. ICDC helped to develop pharmaceutical production in this period through parastatal joint ventures. Dawa was established as a 1970s joint venture between the ICDC and the Yugoslav government. A firm producing infusions, Infusion Medicare, began in the mid-1970s as a joint venture between the ICDC and Hoechst E.A. (the latter the East African arm of a German pharmaceutical producer now part of Sanofi).

ISI policy in this period successfully created an industrial base in Kenya, especially in light consumer industries such as textile and foodstuffs, but also in others such as metal products. Between independence and 1980, industrial output quadrupled, the share of GDP in manufacturing grew from $10.1 \%$ to $13.3 \%$ and the number of industrial establishments more than doubled (Ogonda, 1992: 297-98). The increase in local manufacturing reduced the multinational companies' (MNCs) share of industrial output, which however still accounted for $20 \%$ of industrial output in the early 1970s (Maxon, 1992: 385).

However, the protection from international competition encouraged local firms to focus on the protected local market and neglect exports. This created an anti-export bias that, together with external shocks such 
as the oil crises and a deterioration of terms of trade, led to a shortage of foreign exchange. In 1980 Kenya had to take a loan with the World Bank, which imposed structural adjustment conditions. This marked the beginning of the phase of liberalization and structural adjustment policies in the mid-1980s and 1990s, as it happened across Sub-Saharan Africa, and the beginning of a shift to export promotion. In Kenya, export promotion included a number of measures to allow production for exports using duty-free inputs, but the implementation was slow and tentative, with little impact on export.

The gradual opening up of local markets created competition that had an adverse impact on local industrial activity. Shortage in foreign currency contributed to the decline of domestic industry as firms found it difficult to buy foreign inputs and equipment, with adverse effects on capacity utilization and therefore productivity. After an economic crisis at the beginning of the 1990s, liberalization and export promotion accelerated with the creation of Export Promotion Zones (EPZs), participation in the Common Market for Eastern and Southern Africa (COMESA) and the East Africa Community (EAC), and the removal of price controls in 1994. Export promotion and international competition, however, had little impact on pharmaceuticals in that period. More important was a push in the 1990s to 'buy local', aiming, for example to ensure that basic medicines kits should be 50\% local products (Wamae and Kariuki Kungu, 2014). Local pharmaceutical companies benefitted from this policy - an example of active use of health sector procurement as an industrial policy. Among the larger Kenyan manufacturers, Regal was established in the 1980s and Universal in the 1990s. Parastatal firms were privatized.

The third phase of industrial development, in the new millennium, saw an increase in exports especially in textiles through the United States' African Growth and Opportunity Act (AGOA), which facilitated exports to the US and increased activity in EPZs. In spite of this new push to promote exports, the pressure of global competition from other low-income countries has meant that the share of manufacturing in total GDP has not changed significantly, and much of industrial activity is still carried out in the informal sector by micro enterprises, whose small size makes it difficult to find funds for investment, expansion and upgrading. During these years, most of the foreign MNCs also ceased to produce in Kenya as they reorganized their supply chains globally in the light of competition from China and India to find cheaper locations for production. It is possible that local producers may have benefitted from the flight of production from MNCs, being able to take their place 
in some market segments and absorbing employees already trained by foreign MNCs.

The development of Kenya's pharmaceutical industry suggests that ISI policies were important to build an initial industrial base. Previous analyses of industrialization have argued the ISI policies followed by careful liberalization and export promotion might be useful to promote industrialization (see, e.g., Athreye, 2004, for the Indian software industry). So it is possible that ISI policies enabled Kenya to start the accumulation of basic technological know-how, perhaps through parastatal joint ventures, such as those formed by ICDC, in spite of their problems. The opening up of export markets, especially with the creation of COMESA and EAC and the policies that promoted exports such as the formation of EPZs, also enabled the strongest firms to adapt to international competition and offered opportunities for the expansion that is observed today, as the next section shows.

\section{The Kenyan pharmaceutical industry and its market position}

In historical studies of industrialization in Kenya, the pharmaceutical sector is rarely mentioned as it traditionally accounted for a very small share of industrial output. However, recently its status has been increasingly recognized. For example, pharmaceuticals are mentioned as one of the eighteen strategic sectors in the National Industrialization Policy 2011-15 (Ministry of Industrialization, 2010). Kenyan local manufacturers of medicines have shown great resilience during the years of economic difficulties and are now embarked on a process of growth and technological upgrading that, if successful, can establish them as a major player in the East African market for medicines.

Kenya's pharmaceutical production grew continuously from 2007 to 2013. As Figure 2.1 shows, in that period total production of tablets, capsules, liquid preparations for oral use and creams/ointments alone increased from US\$34.1 million to US\$154 million. The figure also shows that the composition of products has changed over these years, with creams and ointments becoming more popular, although virtually all product types have steadily increased with the possible exception of capsules.

Kenya has also seen strong growth in its pharmaceutical exports in the new millennium, especially since 2002. Exports started growing around 1992-93 thanks to the 'buy local' push, which promoted the expansion of local manufacturing. However, during the 1990s and early 2000s, 


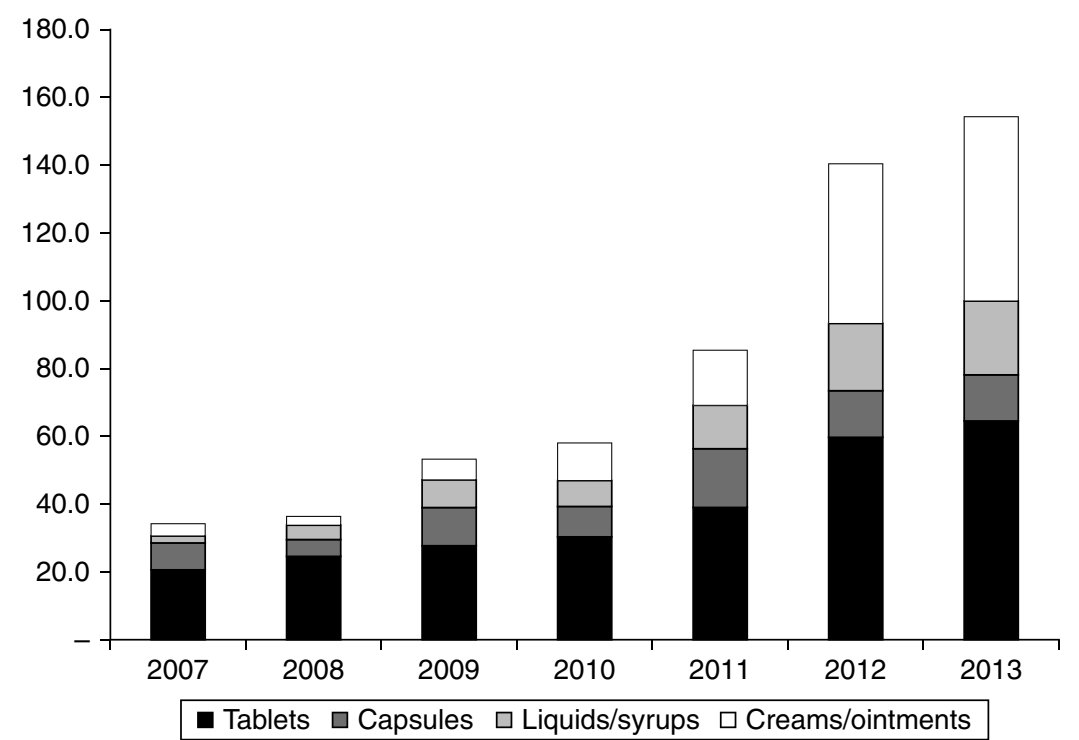

Figure 2.1 Local production of non-parenteral medicines in Kenya by type of product, 2007-13 (US\$ million)

Source: Kenya National Bureau of Statistics, Production data for the period 2007 to 2013, Government of Kenya, Nairobi, obtained 4 September $2014 .^{2}$

local production was affected by the adverse effects of liberalization policies described in the previous section, and exports remained stable. These years also saw a wave of divestments of production activities from foreign-owned companies that carried on in the new millennium as Kenya's industrial environment deteriorated and MNC producers moved out of Kenya to lower cost platforms. By 2014, only one MNC was still manufacturing in Kenya - GSK. Otherwise, pharmaceutical firms in Kenya are currently mainly locally owned.

The great majority of Kenyan's pharmaceutical exports are destined to Sub-Saharan Africa (SSA). COMESA is the main export destination for Kenya's pharmaceutical exports, with Kenya supplying about 50 per cent of the region's production. In relative terms, however, this translates into a minute share of the COMESA market.

With respect to the main importers of Kenya's pharmaceutical products, Uganda has remained a significant market over a number of decades. Somalia and Sudan have also seen significant growth of Kenyan products, particularly over the last two decades. 
In spite of the growth in production and exports, the Kenyan pharmaceutical industry has to overcome important challenges in order to consolidate and expand its influence in the East African region. Kenya's pharmaceutical industry is still mainly oriented towards the home market, with an export share of domestic production only ranging between 15 and 20 per cent, at least up to 2010. Furthermore, the Kenyan producers' share of their own home market is estimated at around 25\% of domestic demand (see also Chapter 8), leaving room for expansion (Wamae and Kariuki Kungu, 2014).

Kenyan manufacturers sell to the Kenyan public procurement agency KEMSA, and to the large non-profit wholesaler the Mission for Essential Drugs Supply (MEDS) that supplies predominantly the faith-based health care sector. They also sell into the large private sector (Chapter 8). Public procurement is regulated by the Public Procurement and Disposal Act of 2005, and tendering decisions are based mainly on pricing, though a $15 \%$ price preference for local manufacturers is available. Producers and distributors are free to set their own prices and mark-ups, and private mark-ups are, on average, high. The pricing of medicines in Kenya was completely liberalized in 1993.

In the new millennium the Kenyan domestic medicines market has been hit by more global competition, notably from South Asia. A key development for the pharmaceutical industry has been the large-scale movement of donors into supplying medicines for malaria, TB and especially HIV/AIDS. This has been a strong influence on the domestic market and pharmaceutical policies in a number of the countries discussed in this book. The arrival of the large donors was, however, somewhat later and more patchy in Kenya than in some neighbouring countries. PEPFAR, for example, the main US programme for funding HIV/AIDS medication, began to operate in Kenya only in 2008, and Kenya received no funding under Rounds 8 and 9 of the Global Fund financing (UNIDO, 2010: 41).

The production capabilities of the Kenyan industry were confirmed during this period by the companies' role in the campaigning that led to the 2001 government decision to allow compulsory licensing of generic production of HIV/AIDS medicines, and the subsequent issuing of voluntary licences (UNIDO, 2010). However, private importers from South and East Asia were increasingly generating price-based competition in the Kenyan medicines market as liberalization took hold. With export figures that in absolute terms remain very modest, it is essential that Kenyan manufacturers keep upgrading and also control costs in order not only to expand its foreign markets but also to keep up with 
increasingly demanding technological standards and cheap foreign competition that creates a serious challenge to local producers.

\section{Technological capabilities and sectoral systems of innovation}

The previous sections have shown that Kenyan pharmaceutical manufacturers are enjoying a period of growth. However they also face challenges that arise from cheap imports and the need to constantly upgrade their technology in order to keep up with global competition and increasingly demanding technical standards and to successfully exploit new market opportunities. A key factor in the future prospects of the Kenyan pharmaceutical industry is therefore the extent to which the local producers will be able to improve their technological capabilities.

The notion of technological capabilities, which has now entered the mainstream analysis of industrial development, can be traced back to the work of evolutionary economists such as Richard Nelson, Sydney Winter, Christopher Freeman and Giovanni Dosi (Dosi et al., 1988; Nelson and Winter, 1982). Evolutionary economics started as a critique of the dominant theoretical framework in economics, the neoclassical approach. The critique arose from the observation that the tools of neoclassical analysis were not well suited to the study of technological and industrial change. Neoclassical economics focuses on the working of the price mechanism in the coordination of economic activity but makes strong and unrealistic assumptions about the nature of technological knowledge and the way firms (and, in general, other economic agents) operate. Technology is seen as information, which has public good features and is therefore easily transferred between firms. Technology transfer is simplistically seen as the transfer of free information.

Evolutionary economists, however, argue that much of technological knowledge is tacit and hence difficult to articulate, let alone transfer easily. The effective use of technology requires that any publicly available technical information be processed using know-how and skills that not only are costly to acquire but also differ across firms, industries and countries. Firms and other organizations, like people, acquire skills, or capabilities, that become embedded in their procedures (also called routines) and people through a process of learning that is shaped by the history of the firm. Technological capabilities, therefore, are the organizational skills that enable firms to make effective use of technologies, including the ability to adapt them, improve them and even develop radically new products and processes. Because of their tacit nature, capabilities 
are costly to acquire, are learned over time and change slowly over time. An important consequence of this view is that since firms' histories and sources of learning differ, the capabilities that firms accumulate also differ. Indeed, industry studies have shown that firms within the same industry usually have many differences that are persistent over time: each firm is unique (Griliches and Mairesse, 1995).

The work on capabilities of early evolutionary economists originally focussed on advanced technologies and firms in industrialized countries. However, other scholars, such as Lall, extended this work into the context of developing countries. In an influential paper, Lall (1992) distinguished between firm-level and country-level capabilities. Firm capabilities include both investment and production capabilities and can be classified according to their degree of complexity, from basic, which involve experience-based tasks, to intermediate, which involve an element of search, to advanced, which are research-based and involve the creation of wholly new products and processes. Firm capabilities also include 'linkage capabilities', the way in which firms learn from and transfer knowledge to the external environment, that is, other organizations and institutions, including customers, suppliers, government agencies and science and technology providers. Countries also have distinctive national capabilities, which are more than the sum of the capabilities of their firms and other organizations because they also include they way economic agents interact and the features of the economic environment, such as the policies, incentives and institutions.

The early work on technological capabilities has been further developed by many scholars and has now entered mainstream thought in the field of science, technology and innovation studies (STI). A useful development of this theorizing is the recognition that industrial sectors have a set of institutions and organizations that differ across sectors and influence the way technological capabilities are accumulated and firms compete. In order to understand an industry's patterns of development and change, it is necessary to study the various agents that influence the accumulation of knowledge and the nature of competition in the industry and the way they interact.

The pharmaceutical sector is a typical example of the distinctiveness of sectoral institutions that shape technological learning and competition. Medicines are usually strictly regulated for their efficacy and safety by government agencies in a way that is unusual in other industries. The structure of demand is also distinctive because of the important role played by the state through the public procurement of essential medicines for the health system and, especially in low-income countries, the 
major role played by international donors in the purchase of key medicines. On the supply side, universities also play an important role as providers of skilled labour and scientific knowledge.

\section{Technological capabilities in manufacturing of medicines in Kenya}

This section draws on various sources, including firm interview data, in order to give an assessment of the Kenyan technological capabilities in the local production of pharmaceuticals. The technological capabilities of the Kenyan domestic pharmaceutical sector are analysed by looking at various dimensions of the production system in which local manufacturers of pharmaceutical operate.

The analysis starts with the description of the local producers because the firms are at the centre of the industrial system. A good starting point for the assessment of the manufacturers' capabilities is the analysis of the characteristics of their products in terms of quality and technological sophistication, the extent to which they achieve industry standards and their productivity. What firms can achieve, however, also depends on the capabilities of the system of suppliers, customers, regulations and institutions with which they interact, including the educational and financial systems, so these aspects will be included in the analysis.

\section{Industrial structure}

Local manufacturing of pharmaceuticals in Kenya is dominated by locally owned firms. In 2014 there were 39 local manufacturing firms with products registered with the Pharmaceuticals and Poisons Board $(\mathrm{PPB})$, the agency that regulates the manufacture and trading of medicines in Kenya. Of these, 34 produced medicines for human consumption, whilst at least five firms produced animal health products. Of the 34 firms, only one producer is a foreign-owned MNC, GSK East Africa, which has not followed the exodus of other MNCs. Although MNCs dominated the local production of pharmaceuticals in Kenya in the 1990s, because of the unattractive economic conditions in Kenya in the 1990s and changes in global supply chains, most of them have moved production facilities to lower cost locations and are only present in Kenya for activities such as marketing and clinical studies (Wamae and Kariuki Kungu, 2014).

However, government policy has provided other incentives for local production by removing import duties and taxes from inputs to 
pharmaceutical products, such as APIs, excipients and packaging materials. The situation, however, changed in 2013 when the new VAT act reintroduced taxation for pharmaceutical inputs and only exempted finished products. This decision made locally produced medicines up to $22 \%$ more expensive, and the industry put pressure on the government to reverse the decision. This happened in the 2014 Act, but there are still some unresolved issues that are worrying local manufacturers (Wamae et al., 2014).

Studies of the Kenyan supply medicines chain show that Kenya has high margins for distributions, which raise the final price of the medicines to users in spite of fairly low manufacturing costs, in comparison to countries, such as Brazil, India, Indonesia, Kenya, Netherlands, Russia and South Africa. The study shows that the percentage of distribution costs is clearly highest in Kenya (see IMS Institute for Healthcare Informatics, 2014: 11). The high margins are a sign of the market power enjoyed by private distributors, who have a global reach and access to cheap imports, mainly from India.

\section{Products and standards}

Kenyan manufacturers are mainly engaging in activities that require basic to moderate technological capabilities, such as formulation activities, that is, converting manufactured bulk substances into final usable forms, and packaging rather than activities at the high end of the technological spectrum, such as $R \& D$ aimed at the discovery of new molecules and product development or the production of bulk pharmaceutical substances (APIs). The tablet is the most common dosage form; Kenyan firms also manufacture capsules, topical preparations (creams, gels, ointments or pastes), liquid preparations for oral use (including syrups), injectable infusions (small and large volume parenteral preparations) and ophthalmic formulations. Topical preparations have seen significant growth between 2007 and 2013 (Figure 2.1) (Wamae and Kariuki Kungu, 2014).

Formulations, however, can vary substantially in terms of the technological capabilities required for production. Products such as injectable infusions and ophthalmic formulations require sterilization, which is achieved through a production process that is technologically complex and demanding in terms of meeting standards of safety, efficacy and quality - particularly for injectable infusions. There are three local firms that manufacture injectable infusions and a few others that produce sterile ophthalmic products, including Laboratories \& Allied (Wamae and Kariuki Kungu, 2014). 
There are also important differences in the technological requirements within the group of non-sterile formulations. Some of the more technologically progressive firms have dedicated laboratories that undertake extensive product development activities with regard to existing products and are developing the capabilities for the production of more technologically sophisticated products. For example, some firms are moving from plain tablets to modified-release and sustainedrelease tablets. Some firms also engage in active process improvements. Some producers already meet WHO-GMP standards, and are also upgrading their production processes to gain WHO recognition, which could possibly open the door to funding by international donor agencies. One company, Universal Corporation, has already received WHO prequalification for its Lamivudine/Zidovudine anti-retroviral product in 2011, and other firms, such as Cosmos, are aiming to gain pre-qualification in the near future. Other firms are attempting to gain GMP standards with the help of PPB and international agencies such as UNIDO (UNIDO, 2014).

Formal R\&D activity (the discovery and product development of new active pharmaceutical ingredients) is in its infancy, with only one firm engaging in R\&D. Another firm, Botanical Extract EPZ (or BEEPZ), is the only Kenyan firm developing capabilities for the production of artemisinin, which is used in the production of anti-malarials. BEEPZ is the development of an industrial concern born in 1996 in Tanzania to develop the production of high-quality artemisia annua with improved yields and artemisinin content. The project expanded its facilities to produce the raw materials in Kenya and Uganda, and in 2007 BEEPZ commissioned its principal processing facility in the export processing zone (EPZ) in Athi River, Kenya, currently producing non-API-grade artemisinin for export (Botanical Extracts EPZ, 2015). The expansion of production of artemisia annua to Kenya and Uganda was possible thanks to grants from the UK Department for International Development (DFID) and the multinational company Novartis, a leading producer of artemisinin-based anti-malarial drugs, which also became a BEEPZ customer in 2009, when the EPZ plant started production (IRIN News Africa, 2015).

There are also three local firms that process some raw materials that are used to manufacture bulk pharmaceutical products. These raw materials are $100 \%$ destined for export, as the local capacity for manufacturing active pharmaceutical ingredients remains underdeveloped. 


\section{Productivity, capacity utilization and cost efficiency}

Unfortunately, it is too difficult to obtain a direct measure of productivity for the various manufacturers, but it is well known that capacity utilization is an important determinant of productivity. Firms that only operate at a low level of capacity utilization are less efficient and can only achieve relatively low levels of productivity.

Annual capacity utilization for the manufacture of most dosage forms averages around $60 \%$. Only injectable infusions experience higher capacity utilization ranging between 85 and $100 \%$. A number of reasons have been identified from interview data. These include: the functioning state of machinery and equipment; delays in sourcing spare parts from abroad and specialized maintenance support from machinery and equipment suppliers; human resource issues and in particular highly specialized skills in some critical areas such as product development; perceptions of locally manufactured products by some market segments; and lack of policy coherence (Wamae and Kariuki Kungu, 2014). Some of these challenges have a direct impact on the competitiveness of locally manufactured products.

The interesting observation is that these factors seem to apply mainly to the supply side of the industry. In other words, limited capacity utilization does not seem to be due to lack of demand. The previous sections showed that local producers only supply a quarter of the domestic market and a very small fraction, less that $1 \%$, of the COMESA medicines market, so there are plenty of opportunities for expansion. Indeed, Kenyan local manufacturers have the twofold challenge of having to increase capacity utilization and very importantly considering options for expanding their total capacity.

On the other hand, once the segments in which local producers operate, which are mainly fairly unsophisticated formulations of essential medicines, are taken into account, it is possible to see that Kenyan manufacturers operate in a very competitive sub-section of the market with many competitors, both domestic and importers, and where prices and therefore profit margins are low because of the low purchasing power of the consumers and the inability to access funding from donors because of lack of WHO prequalification (UNIDO, 2012). So the technological limitations of the manufacturers also contribute to relegating most of them to a narrow and highly competitive segment of the industry where demand for each firm's product might well be constrained in some cases. 


\section{Human resources and the educational system}

Successful industrial production requires a range of different skills. Local universities, such as Jomo Kenyatta University of Agriculture and Technology, Mount Kenya University and the University of Nairobi, provide graduates with good-quality basic skills and training in pharmacy, engineering and chemistry. Top polytechnics such as the Kenya Medical Training College are good sources for mid-level training. Employees also use foreign universities, for example in the UK, Germany and India. All firms also have compulsory training in-house. However, the internal education system cannot meet all industry requirements, especially as upgrading is needed.

Official reviews (UNIDO, 2012) and interviews suggest that there is a scarcity of pharmacists specialized in industrial pharmacy. The educational system has a high literacy rate and provides people well qualified in clinical pharmacy, but newly qualified employees need extensive training in the industrial aspects of drug production, including specialized training in industrial quality assurance. A key issue is that the teachers were originally trained in clinical pharmacy, so there is not a long tradition of industrial pharmacy in Kenya. University graduates have a good training in basic skills and theory, but many firms make use of training programmes run both internally and externally by international organizations, such as GIZ, Action Medeor and UNIDO. The latter sponsors popular courses such as the industrial pharmacy advanced training course run in Tanzania at the Kilimanjaro School of Pharmacy with the support of US universities (UNIDO, 2015).

Firms use some local training institutions, both public, such as the Kenya Medical Research Institute (KEMRI) and the PPB, and private. For advanced skills, however, they need to bring in experts from abroad, usually from India but also from other countries. Expatriates are expensive but important for quality because they have rare skills and experience in industrial processes. Usually they are offered shortterm contracts (two to three years), possibly renewed once but usually not longer because of permit limitations and because new people tend to have more up-to-date skills. Foreign experts are identified through various channels, such as suppliers, agencies, the Web, competitors and international agencies.

Finally, in some cases firms also use their informal networks to send employees to be trained abroad, with India being a popular destination because of the strength of the Indian pharmaceutical industry. So local manufacturers seem to be able to rely on solid internal supply of skills, 
although at a fairly basic level, and to access expertise at a global scale even though the latter is subject to intense scrutiny because of its high costs.

\section{Equipment and inputs}

The shallow level of the Kenyan industrial sector is an important factor when inputs to production and equipment are considered. Kenya's industry is one of the most developed in East Africa, and local producers can find local suppliers for basic inputs including packaging, with the exception of some more advanced packaging for sterile products, which is procured abroad, for example from China. Some more technologically complex packaging, such as over-pouches for injectables, used to be imported but are now produced locally.

Raw materials for production are mainly imported, due to the lack of producers of APIs and excipients. This dependence on imports is an important issue because it generates possible shortages which might influence production capacity, and additional costs even though pharmaceutical inputs are supposed to be exempted from duties. In addition, Kenyan firms compete with imports produced by vertically integrated companies who also produce APIs, and are likely to price this key ingredient above the competitive level.

Kenya does not have a developed industrial machinery sector, so the main machinery is imported from international suppliers. A popular source of equipment for pharmaceutical production is India followed by China, although language can be a barrier. India's machines have the advantage of being significantly cheaper than those from industrialized countries and basically do the work well enough for tasks that do not require a high level of technological sophistication. Europe (especially Germany and Italy) and other high-income countries are the sources of more advanced and reliable machinery. The choice of suppliers is sometimes dictated by financial considerations: higherquality machinery might be not only more efficient but also more profitable in the long run. Companies, however, lack the resources for a high upfront investment in European machinery, in spite of the fact that the financial sector in Kenya is the most developed in East Africa.

The dependence on imports of machinery creates additional costs for local firms. Spare parts attract additional costs because imported products need to be checked and to obtain a quality stamp according to rules of the Kenyan Bureau of Standards. Additional inefficiencies are also created by the lags that occur in decisions during the process of import. 
Machines are operated by local engineers, who also keep records for GMP inspections, and are usually installed by suppliers who offer a comprehensive package of support including training and maintenance, at least for the first few years of life of the machines.

Some companies are currently looking to automate their production processes. Reduction of labour costs is one of the reasons, but improvement of quality and productivity and reduction of human error and exposure in handling are more important factors.

\section{Knowledge flows, linkage capabilities and innovation}

As explained above, capabilities at the industry level depend not only on the capabilities of the various economic agents, such as manufacturers, but also on how effectively the various components of the industrial system interact and promote flows of knowledge. This section, therefore, looks in more detail at the flows of knowledge in the system and how these influence the accumulation of capabilities within firms.

Medicine producers develop their capabilities by acquiring knowledge from the external environment and through experience accumulated through a process of learning-by-doing over time. An important input to the firms' capabilities comes from the education and training activities of its workers, as discussed above. Firms, however, can step up their accumulation of knowledge by explicitly investing in learning. This can happen internally through formal or informal research activities and by acquiring knowledge from other firms - suppliers, customers and even competitors - or research institutions. Most of the firms interviewed mentioned the importance of suppliers as sources of useful knowledge. Suppliers regularly train manufacturers' employees to use their machinery. Furthermore, by coming into contact with many different firms, suppliers gain useful knowledge about the industry and can be used as sources of technological knowledge or to identify people and firms with specific expertise that is useful for a company. Since Kenyan firms use foreign suppliers, they have been able to tap into their suppliers' knowledge networks in order to identify foreign experts to hire, good training programmes and foreign firms where they can send their employees to learn more about advanced industrial technologies: some firms, for example, have mentioned examples of employees sent to be trained in Indian firms.

As mentioned above, firms also gain valuable knowledge by hiring international experts from countries such as India, South Africa and even European countries. Hiring expatriates and sending employees 
to train abroad are expensive investments, so firms have schemes in which the trained employees relay the knowledge learnt to their colleagues.

As the innovation literature has pointed out since the work of Von Hippel, firms also learn from the users of their products (Von Hippel, 1982). Some producers have stressed the importance of the feedback collected by their marketing teams. A firm selling sterile injectable products stated that important knowledge was learned from nurses who used their products, and changes were implemented following the nurses' feedback.

Other common channels through which firms learn useful knowledge are exhibitions (also abroad), websites, membership of professional associations and conferences. Manufacturers also learn from each other because employees move between firms or meet and have informal exchanges at training events and seminars. Flows of knowledge also occur through the industry associations, the Federation of Kenyan Pharmaceutical Manufacturers (KFPM) and the Federation of East African Pharmaceutical Manufacturers (EAFPM), which organize training events and other initiatives.

Regulatory agencies also provide firms with valuable knowledge. For example, PPB does not only carry out inspections but also helps manufacturers with advice, especially on issues relating to the acquisition of the GMP standard, including documentation relating to the audits, and on Good Laboratory Practice and Good Distribution Practice. Similarly, the National Quality Control Laboratory (NQCL) offers training and knowledge transfer in the areas of drug testing and medical instrumentation, and Kenya Medical Research Institute (KEMRI) collaborates in the areas of research and training (KEMRI, 2015).

\section{Licensing and joint ventures: the role of government policy}

As the previous section has explained, the accumulation of technological capabilities occurs over time, and the current capabilities are influenced by past events. Because of the cumulative nature of technological knowledge, policy initiatives can have a long-lasting impact on the capabilities of firms and industries. In the Kenyan case, there are two examples of policy intervention that can be said to have helped the development of technological capabilities in the industry: the provisions for compulsory licensing in the Trade-Related Aspects of Intellectual Property Rights (TRIPS) negotiations, and the policy of forming parastatal joint ventures with foreign MNCs in order to develop local capabilities based on foreign technology. 
In the case of licensing of foreign technology, Kenya campaigned vigorously during the trade negotiations that led to the TRIPS agreement in order to be able to carry out compulsory licensing for some essential medicines. Compulsory licensing means that governments can issue licenses to manufacture medicines that are still protected by patents at more affordable prices than those set by foreign pharmaceutical companies that hold the patents, without receiving the latter's consent. Although in practice there has been no compulsory licensing in Kenya, it can be argued that the threat of compulsory licensing has enabled local firms to reach good licensing agreements with foreign MNCs. According to Garwood (2007), 'Kenya has never issued a compulsory license, but came close to in 2004 before the German pharmaceutical major Boehringer Ingelheim agreed to enter into a voluntary license agreement with Kenyan drug firm Cosmos to produce generic versions of its patented anti-AIDS drug nevirapine'. Cosmos went on to enter another technology transfer agreement with Roche and is now one of the most dynamic Kenyan manufacturers, also aiming to gain WHO prequalification for the production of ARVs. The 'buy local' drive or procurement approach of the 1990s was also significant. It helped to lay a strong basis for the mushrooming of private local manufacturers: thus Cosmos would probably not have had its advantageous licensing position were it not for the 'buy local' move that was in effect very much steeped in ISI thinking.

As the above historical background pointed out, during the import substitution period, the government established ICDC to promote the development of local capabilities partly through parastatal joint ventures with foreign organizations. Joint ventures formed through the 1970s with the Yugoslav government and a German firm are now the precursors of two dynamic Kenyan private firms: Dawa and Infusion Medicare, one of the producers of injectables. Cosmos was also originally formed as a joint venture. Now all three firms are wholly locally owned private firms, and critics of import substitution and ICDC interpret the fact that the joint ventures had to be privatized as a failure of import substitution and ICDC (see, for instance, Himbara, 1993). However, it can be argued that although the parastatal status might have hindered the business development of the joint ventures, ICDC can still be said to be responsible for the creation of organizations that developed local technological capabilities that were later further developed by private capital. Possibly, without the initial policy of forming joint venture, companies like Dawa, Infusion Medicare and Cosmos would not exist today. 
The ISI policy involving joint ventures, of course, is not the only way to build industrial capabilities. In more recent years, Kenyan firms have found other ways to draw successfully on foreign capabilities. Two other producers of sterile products followed different strategies: one, facilitated by the assurance of a large government procurement, bought a South African firm outright and transferred the facilities to Kenya, whilst the other, which pursued an export-oriented strategy and is located in an EPZ, assembled a variety of suppliers and contractors to build a new plant with equipment sourced from various countries and drawing on international expertise.

\section{Conclusions}

This chapter has provided an outline of the local production of medicines in Kenya, which is the leading manufacturer of pharmaceuticals in East Africa, accounting for half of the local production in COMESA and boosting rising production and exports. The Kenyan pharmaceutical industry is still small in relation to imports into Kenya and the whole of COMESA. However it constitutes a story of successful development of technological capabilities with examples of firms that are upgrading their technology and might be able to become leading players in East Africa, such as Universal, which has achieved enough technological capabilities to be awarded WHO prequalification. Kenya's dynamic private sector and its access to COMESA and EAC are important strengths that suggest good prospects for Kenyan local producers.

However, obstacles and limitations remain, and the analysis in this chapter has shown that Kenyan firms have to upgrade successfully in order to compete effectively against strong imports. Kenyan pharmaceutical producers have not yet been able to access donor funding, with only one firm achieving WHO prequalification so far. Most of the firms also operate in a highly competitive segment of the industry, the production of formulations of essential medicines, which offers low returns and pits them against very efficient imports. There are, however, success stories of firms that have reached significant technological sophistication, as in the case of the producers of injectables, and the analysis paints the picture of an industry integrating in global value chains, with access to global networks of equipment suppliers, foreign experts and training centres.

Still, there is work to be done to improve the regulatory environment, such as making sure that the VAT regulations do not disadvantage local firms, reducing the dependence of local manufacturers on imported raw 
materials and promoting upgrading throughout the technologically weaker firms; the current strategy is to progressively move all firms from local to international GMP standards.

It is not straightforward to draw general lessons for the promotion of local production of pharmaceuticals in low-income countries given the messy economic history and diverse patterns of technological accumulation this chapter has presented. It is possible, however, to suggest some possible tentative reasons that might have contributed to the observed successes of Kenyan pharmaceutical production. The chapter has argued that ISI policies, including the use of joint ventures at an early stage of industrialization, followed by gradual liberalization, might have been a positive factor in the accumulation of technological capabilities. Kenyan producers seem also to access global networks that are useful to identify and tap into rare skills and identify good equipment suppliers. The openness of Kenyan manufacturers may also be assisted by India-linked networks of some manufacturers with accumulated family experience in capitalist production from older merchant enterprises (Himbara, 1993).

On the whole, this chapter suggests a positive future for broadening and deepening pharmaceuticals production in Kenya. Despite an international and national context that is often less than helpful, considerable progress has been made in the past few years and capabilities have been established that, while often unseen, are laying the basis for further growth. With a little extra help at the government level, Kenya might soon be a leading African nation in the field.

\section{Notes}

1. Research project Industrial productivity and health sector performance. The findings, interpretations, conclusions and opinions expressed here are those of the authors and do not necessarily reflect the views or policies of DFID or the UK ESRC, whose financial support is gratefully acknowledged (project ES/ J008737/1). This chapter draws on fieldwork undertaken by Watu Wamae and Joan Kariuki Kungu as part of that research project.

2. An earlier version of this figure appears in Wamae and Kariuki Kungu (2014), reworked with permission.

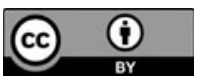

Except where otherwise noted, this work is licensed under a Creative Commons Attribution 4.0 Unported License. To view a copy of this license, visit https://creativecommons.org/version4 